\title{
FAKTOR RISIKO HEMORRHAGE PASCA POST PARTUM
}

\author{
Annisa Ul-Ilmi, Serilaila, Reka Lagora Marsofely
Politeknik Kesehatan Kementerian Kesehatan Bengkulu, Jurusan Kebidanan, Jalan Indragiri Nomor 03 Padang Harapan Bengkulu
ulilmiannisa9@gmail.com

\begin{abstract}
Bleeding is one of the causes of maternal deaths at Curup General Hospital in 2016 with the number of cases as many as 123 cases. Many factors affect the occurrence of postpartum bleeding such as parity, birth spacing, age and anemia. This study aims to determine the risk factors that affect post partum hemorrhage at Curup General Hospital District Rejang Lebong Year 2016. Descriptive analytic research method with case control design. The sample was 246 with ratio 1 between case group and control group (123). Data were analyzed by univariate, bivariate and multivariate using cgi square test and binary logistic regression. There was no correlation between birth and postpartum hemorrhage ( $\mathrm{p}$-value $=0.199, \mathrm{OR}=1.392$ ), there was a correlation between birth age and postpartum hemorrhage ( $\mathrm{p}$-value $=0.002, \mathrm{OR}=2.220$ ) and no anemia relationship with postpartum hemorrhage $(\mathrm{p}$-value $=0.294$, OR $=0.759)$. The most influential factors for post partum bleeding were parity ( $\mathrm{p}$-value $=0.044$, $\mathrm{OR}=0.589$ ). Especially in mothers to be delivered in specific and comprehensive detection especially for mother primi or grandemultipara especially at the time of III and IV by doing active management action of third stage so as to prevent the occurrence of uterine atony.
\end{abstract}

Keywords : Anemia, Birthage, Parity, Postpartum Bleeding, Age

\begin{abstract}
Abstrak : Perdarahan merupakan salah satu penyebab kematian ibu di Rumah Sakit Umum Daerah Curup tahun 2016 dengan jumlah kasus sebanyak 123 kasus. Banyak faktor yang mempengaruhi terjadinya perdarahan post partum diantaranya paritas, jarak kelahiran, umur dan anemia. Penelitian ini bertujuan untuk mengetahui faktor risiko yang mempengaruhi perdarahan post partum di Rumah Sakit Umum Daerah Curup Kabupaten Rejang Lebong Tahun 2016. Metode penelitian deskriptif analitik dengan desain case control. Sampel berjumlah 246 dengan perbandingan 1 antara kelompok kasus dan kelompok kontrol (123). Data dianalisis secara univariat, bivariat dan multivariat dengan menggunakan uji cgi square dan regresi binary logistic. Hasil penelitian ada hubungan paritas dengan perdarahan post partum ( $p$-value $=0.041, \mathrm{OR}=1.691)$, tidak ada hubungan jarak kelahiran dengan perdarahan post partum ( $p$-value $=0.199, \mathrm{OR}=1.392$ ), ada hubungan umur kelahiran dengan perdarahan post partum $(p$-value $=0.002, \mathrm{OR}=2.220)$ dan tidak ada hubungan anemia dengan perdarahan post partum ( $p$-value $=0.294, \mathrm{OR}=0.759)$. Faktor yang paling berpengaruh terhadap perdarahan post partum adalah paritas ( $p$-value $=0.044$, $\mathrm{OR}=0.589$ ). Khusus pada ibu yang akan bersalin dlakukan deteksi yang spesifik dan komprehensif terutama bagi ibu primi atau grandemultipara terutama pada saat kala III dan IV dengan melakukan tindakan manajemen aktif kala III sehingga mencegah terjadinya atonia uteri.
\end{abstract}

Kata Kunci : Anemia, Jarak Kelahiran, Paritas, Perdarahan Postpartum, Usia

World Health Organization (WHO) memperkirakan 800 perempuan meninggal setiap harinya akibat komplikasi kehamilan dan proses kelahiran. Sekitar 99\% dari seluruh kematian ibu terjadi di negara berkembang. Sekitar $80 \%$ kematian maternal merupakan akibat meningkatnya komplikasi selama kehamilan, persalinan dan setelah persalinan (WHO, 2014).

Data menurut Profil Kesehatan Indonesia tahun 2014 empat penyebab kematian ibu terbesar yaitu perdarahan 30,3\%, Hipertensi Dalam Kehamilan (HDK) $27,1 \%$, infeksi $7,3 \%$, dan lain-lain yaitu penyebab kematian ibu tidak langsung seperti kondisi penyakit kanker, ginjal, jantung atau penyakit lain yang diderita ibu sebesar 35,3\% (Kemenkes RI, 2014). Kematian ibu di Indonesia juga diimbangi dengan Angka Kematian Ibu (AKI) di Indonesia masih sangat tinggi, pada tahun 2012 AKI di Indonesia sebesar 359/100.000 
kelahiran hidup (BPS, 2012). AKI ini masih sangat jauh dari target Sustainable Development Goals (SDG's) untuk menurunkan AKI menjadi 70/100.000 kelahiran hidup (BAPPENAS, 2017).

Kejadian perdarahan post partum di negara berkembang berkisar antara 5\%$15 \%$. Selanjutnya, kejadian perdarahan post partum ditinjau dari penyebabnya didapatkan data kejadian atonia uteri sebesar (50\%-60\%), sisa plasenta (23\%$24 \%)$, retensio plasenta (16\%-17\%), laserasi jalan lahir (4\%-5\%) dan kelainan darah (0,5\% - 0,8\%) (Nugroho, 2012).

Faktor-faktor yang mempengaruhi kejadian perdarahan postpartum terdiri dari partus lama, paritas, jarak kelahiran, umur, anemia (Saktriyandri, 2017). Wanita dengan riwayat paritas lebih dari sama dengan 4 kali beresiko mengalami. Paritas 2-3 bisa terjadi karena disebabkan karena uterus yang terlalu meregang (bisa juga karena hidramion, hamil ganda, anak besar), kelelahan akibat proses persalinan atau partus lama, penggunaan oksitosin yang berlebihan dalam persalinan pada saat induksi partus, memiliki riwayat perdarahan pada persalinan sebelumnya atau riwayat plasenta manual (Rifdiani, 2016).

Paritas yang rendah (paritas satu) bisa menyebabkan perdarahan karena ketidaksiapan ibu dalam menghadapi persalinan yang pertama dan bisa juga disebabkan karena adanya laserasi jalan lahir. Penelitian Puspasari (2017) terdapat hubungan antara variabel paritas dengan variabel perdarahan postpartum. Besarnya risiko relatif pendarahan postpartum pada kelompok ibu dengan paritas $>4$ memiliki risiko 7 kali dibandingkan kelompok ibu dengan paritas 2 - 4 .

Jarak kehamilan terlalu dekat maka cenderung menimbulkan kerusakan pada system reproduksi wanita baik secara fisiologis ataupun patologis sehingga memberi kemungkinan terjadi anemia pada ibu bahkan sampai dapat menimbulkan kematian (Sawitri et al, 2014). Penelitian Rifdiani (2016) terdapat hubungan antara jarak kelahiran dengan perdarahan post partum. Risiko ibu mengalami perdarahan dengan jarak kehamilan $<2$ tahun adalah 17,953 kali lebih besar dibandingkan dengan ibu yang jarak kehamilannya $\geq 2$ tahun.

Umur paling aman bagi seorang wanita untuk hamil dan melahirkan adalah umur antara 20 - 35 tahun, karena mereka berada dalam masa reproduksi sehat. Perdarahan banyak terjadi pada umur $<20$ tahun disebabkan karena belum matangnnya alat reproduksi dan umur > 35 tahun terjadi kemunduran alat-alat reproduksi (Manuaba, 2012). Penelitian Purwanti dkk (2015) ada hubungan antara umur dengan perdarahan post partum karena atonia uteri. Risiko ibu yang memiliki umur kurang dari 20 tahun dan lebih dari 35 tahun 2.1 lebih besar mengalami perdarahan post partum dibandingkan dengan ibu yang berumur 2030 tahun.

Ibu hamil yang mengalami anemia menyebabkan jumlah oksigen yang diikat dalam darah juga sedikit, sehingga mengurangi jumlah pengiriman oksigen dan cakupan nutrisi ke uterus yang menyebabkan kontraksi uterus tidak adekuat sehingga menyebabkan perdarahan (Fitria, 2016). Penelitian Saktriyandri (2017) menyatakan bahwa terdapat hubungan antara anemia dengan perdarahan postpartum di RSUD Panembahan Senopati Bantul Tahun 2015 dan ibu yang bersalin dengan anemia memiliki peluang 4,8 kali mengalami perdarahan postpartum dibanding ibu yang tidak anemia.

Rumah sakit merupakan tempat pelayanan rujukan kegawatdaruratan dari tingkat primer, perdarahan post partum merupakan salah satu kasus yang penanganannya dilakukan di Rumah Sakit. Survey awal yang dilakukan di Rumah sakit Bhayangkara, Rumah sakit Umum Daerah M. Yunus dan Rumah Sakit Umum Daerah Curup Kabupaten Rejang Lebong. Data di Rumah Sakit Bhayangkara didapatkan kejadian perdarahan post partum sebanyak 14 kasus $(3,2 \%)$ pada tahun 2015 dan meningkat pada tahun 2016 sebanyak 30 
kasus (5,7\%). Data yang didapatkan dari sakit Umum Daerah M. Yunus tahun 2016 didapatkan jumlah perdarahan post partum sebanyak 55 kasus (7,5\%). Data yang didapatkan kasus di Rumah Sakit Umum Daerah Curup Kabupaten Rejang Lebong didapatkan jumlah kasus perdarahan post partum pada tahun 2015 sebanyak 37 kasus $(6,8 \%)$ dan meningkat pada tahun 2016 sebanyak 123 kasus $(10,16 \%)$.

Data diatas menunjukkan bahwa kasus perdarahan post partum di Rumah Sakit Umum Daerah Curup Kabupaten Rejang Lebong lebih tinggi dibandingkan dengan kasus di Rumah Sakit lain di Provinsi. Selain itu terjadi peningkatan kasus dari tahun 2015 ke tahun 2016 dan belum adanya dilakukan penelitian di Rumah Sakit Umum Daerah Curup Kabupaten Rejang Lebong.

Data persalinan pada bulan Juli 2017 sebanyak 50 persalinan dengan rincian kasus perdarahan sebanyak 12 kasus (24\%) yang terdiri dari laserasi jalan lahir sebanyak 4 kasus (8\%), atonia uteri 5 kasus (10\%), retensio plasenta 3 kasus (6\%). Selanjutnya, dari 12 kasus perdarahan yang terjadi didapatkan paritas multi sebanyak 6 orang, primi 4 orang dan grande sebanyak 2 orang. Kemudian, ibu dengan anemia sebanyak 5 orang dan tidak anemia sebanyak 7 orang. Jarak kelahiran $\leq 2$ tahun sebanyak 9 orang dan jarak kelahiran $>2$ tahun sebanyak 3 orang. Ibu dengan umur $<20$ tahun sebanyak 2 orang, umur 20-35 tahun 6 orang dan umur $>35$ tahun sebanyak 4 orang.

Berdasarkan data register rumah sakit adanya peningkatan kasus perdarahan post partum di Rumah Sakit Umum Daerah Curup Kabupaten Rejang Lebong dari tahun 2015 ke tahun 2016 sehingga perlu diadakan tindak lanjut mengenai apa saja faktor risiko yang mempengaruhi perdarahan post partum di Rumah Sakit Umum Daerah Curup Kabupaten Rejang Lebong Tahun 2016.

\section{BAHAN DAN CARA KERJA}

Metode penelitian deskriptif analitik dengan desain case control. Sampel berjumlah 246 dengan perbandingan 1 antara kelompok kasus dan kelompok kontrol (123). Data dianalisis secara univariat, bivariat dan multivariat dengan menggunakan uji cgi square dan regresi binary logistic.

\section{HASIL}

Tabel 1. Distribusi Frekuensi Penyebab Perdarahan di RSUD Curup Kabupaten Rejang Lebong Tahun 2016

\begin{tabular}{lcc}
\hline \multicolumn{1}{c}{ Variabel } & $\begin{array}{c}\text { Jumlah } \\
(\mathrm{n}=246)\end{array}$ & $\%$ \\
\hline Penyebab Perdarahan & & \\
Atonia Uteri & 55 & 44.7 \\
Retensio Plasenta & 25 & 20.3 \\
Laserasi Jalan Lahir & 38 & 31 \\
Sisa Plasenta & 5 & 4 \\
\hline Paritas & & \\
Primi dan grande & 116 & 47.2 \\
Multipara & 130 & 52.8 \\
\hline Jarak Kelahiran & & \\
$<2$ tahun & 108 & 43.9 \\
$>=2$ tahun & 138 & 56.1 \\
\hline Umur & & \\
$<20$ dan $>35$ tahun & 112 & 45.5 \\
20-35 tahun & 134 & 54.5 \\
\hline Anemia & & \\
Anemia & 94 & 38.2 \\
Tidak Anemia & 152 & 61.8 \\
\hline
\end{tabular}

Tabel 1 hampir setengah $(44.7 \%)$ penyebab perdarahan atonia didapatkan bahwa sebagian besar $(52.8 \%)$ ibu bersalin memiliki paritas multipara, sebagian besar $(56.1 \%)$ memliliki jarak kelahiran $\geq 2$ tahun, sebagian besar $(54.5 \%)$ memiliki umur 2035 tahun dan sebagian besar $(61.8 \%)$ tidak anemia.

Tabel 2. Hubungan Paritas dengan Perdarahan Post Partum di RSUD Curup Kabupaten Rejang Lebong Tahun 2016

\begin{tabular}{lccccccc}
\hline & \multicolumn{5}{c}{ Perdarahan } & & OR \\
\cline { 2 - 5 } Variabel & \multicolumn{2}{c}{ Ya } & \multicolumn{2}{c}{ Tidak } & - & $(\mathbf{9 5 \%}$ \\
& F & $\%$ & F & $\%$ & $\begin{array}{l}\boldsymbol{p} \text { value } \\
\text { CI) }\end{array}$ \\
\hline Paritas & & & & & & \\
$\begin{array}{l}\text { Primi dan } \\
\text { grande }\end{array}$ & 66 & 53.7 & 50 & 40.7 & 0.041 & 1.691 \\
Multipara & 57 & 46.3 & 73 & 59.3 & & $2.801)$ \\
\hline Total & 123 & 100 & 123 & 100 & & \\
\hline
\end{tabular}


Hasil penelitian didapatkan dari 123 responden yang perdarahan sebagian besar (53.7\%) paritas primi dan grande, dari 123 responden yang tidak mengalami perdarahan sebagian besar $(59.3 \%)$ memiliki paritas multipara. Hasil uji statistik didapatkan $p$ value $=0.041$ artinya ada hubungan paritas dengan perdarahan post partum. Nilai $\mathrm{OR}=1.691$ artinya paritas primipara dan grandemultipara 1.691 kali beresiko mengalami perdarahan post partum dibandingkan paritas multipara.

Tabel 3. Hubungan Jarak Kelahiran dengan Perdarahan Post Partum di RSUD Curup Kabupaten Rejang Lebong Tahun 2016

\begin{tabular}{lcccccc}
\hline & \multicolumn{9}{c}{ Perdarahan } & & OR \\
\cline { 2 - 5 } Variabel & \multicolumn{2}{c}{ Ya } & \multicolumn{2}{c}{ Tidak } & p-value & $\begin{array}{c}\text { (95\% } \\
\text { CI) }\end{array}$ \\
\hline Jarak & F & $\%$ & F & $\%$ & & \\
$<2$ tahun & 59 & 48.0 & 49 & 39.8 & 0.199 & 1.392 \\
$\geq 2$ tahun & 64 & 52.0 & 74 & 60.2 & & $(0.84-$ \\
\hline Total & 12 & 100 & 12 & 100 & & \\
\hline
\end{tabular}

Hasil penelitian didapatkan dari 123 responden yang mengalami perdarahan postpartum sebagian besar $(52 \%)$ memiliki jarak $\geq 2$ tahun, dari 123 responden yang tidak mengalami perdarahan sebanyak sebagian besar $(60.2 \%)$ memiliki jarak kelahiran $\geq 2$ tahun. Hasil uji statistik didapatkan $p$-value $=0.199$ artinya ada tidak ada hubungan jarak kelahiran dengan perdarahan post partum. Nilai $\mathrm{OR}=1.392$ artinya jarak kelahiran <2 tahun 1.392 kali beresiko mengalami perdarahan post partum dibandingkan jarak kelahiran $\geq 2$ tahun.

Tabel 4 Hubungan Umur dengan Perdarahan Post Partum di RSUD Curup Kabupaten Rejang Lebong Tahun 2016

\begin{tabular}{|c|c|c|c|c|c|c|}
\hline \multirow{3}{*}{ Variabel } & \multicolumn{4}{|c|}{ Perdarahan } & \multirow[b]{3}{*}{$\begin{array}{l}p \text { - } \\
\text { value }\end{array}$} & \multirow{3}{*}{$\begin{array}{c}\text { OR } \\
(95 \% \\
\text { CI }) \\
\end{array}$} \\
\hline & \multicolumn{2}{|c|}{ Ya } & \multicolumn{2}{|c|}{ Tidak } & & \\
\hline & $\mathbf{F}$ & $\%$ & $\mathbf{F}$ & $\%$ & & \\
\hline Umur & & & & & & \\
\hline
\end{tabular}

\begin{tabular}{|c|c|c|c|c|c|c|}
\hline$<20$ dan & 68 & 55.3 & 44 & 35.8 & 0.002 & 2.220 \\
\hline$>35$ & 55 & & & & & $\begin{array}{c}(1.330 \\
-\end{array}$ \\
\hline $20-35$ & 55 & 44.7 & 79 & 64.2 & & 3.705) \\
\hline Total & 123 & 100 & 123 & 100 & & \\
\hline
\end{tabular}

Hasil penelitian didapatkan dari 123 responden yang mengalami perdarahan postpartum sebagian besar $(55.3 \%)$ memiliki umur <20 dan >35 tahun, dari 123 responden yang tidak mengalami perdarahan sebagian besar $(64.2 \%)$ memiliki umur 2035 tahun. Hasil uji statistik didapatkan $p$ value $=0.002$ artinya ada hubungan umur dengan perdarahan post partum. Nilai dengan $\mathrm{OR}=2.22$ artinya umur $<20$ dan $>35$ tahun 2.22 kali beresiko mengalami perdarahan post partum dibandingkan umur 20-35 tahun.

Tabel 5. Hubungan Anemia dengan Perdarahan Post Partum di RSUD Curup Kabupaten Rejang Lebong Tahun 2016

\begin{tabular}{lcccccc}
\hline & \multicolumn{9}{c}{ Perdarahan } & & \multicolumn{1}{c}{ OR } \\
\cline { 2 - 5 } Variabel & \multicolumn{2}{c}{ Ya } & \multicolumn{2}{c}{ Tidak } & & (95\% \\
& F & $\%$ & F & $\%$ & $\begin{array}{l}\text { value } \\
\text { CI) }\end{array}$ \\
\hline Anemia & & & & & & \\
Anemia & 43 & 35. & 51 & 41.5 & 0.29 & 0.759 \\
Tidak & 80 & 65. & 72 & 58.5 & & $1.271)$ \\
anemia & & 0 & & & & \\
\hline Total & 123 & 100 & 12 & 100 & & \\
\hline
\end{tabular}

Hasil penelitian didapatkan dari 123 responden yang mengalami perdarahan sebagian besar (65\%) tidak anemia, dari 123 responden yang tidak mengalami perdarahan sebagian besar $(58.5 \%)$ tidak anemia. Hasil uji statistik didapatkan $p$ value $=0.294$ tidak ada hubungan anemia dengan perdarahan post partum. Nilai $\mathrm{OR}=0.759$ artinya anemia 0.759 kali beresiko mengalami perdarahan dibandingkan ibu yang tidak anemia. 
Tabel 6. Hasil Interprestasi Akhir Analisa Multivariat

\begin{tabular}{|c|c|c|c|c|c|}
\hline \multirow[t]{2}{*}{ Model } & \multirow[t]{2}{*}{ Variabel } & \multirow[b]{2}{*}{ Sig. } & \multirow[b]{2}{*}{$\operatorname{Exp}(B)$} & \multicolumn{2}{|c|}{$\begin{array}{c}\text { 95.0\% C.I.for } \\
\operatorname{EXP(B)}\end{array}$} \\
\hline & & & & Lower & Upper \\
\hline \multirow[t]{3}{*}{ I } & Usia & 0.003 & 0.405 & 0.222 & 0.738 \\
\hline & Paritas & 0.035 & 0.567 & 0.335 & 0.961 \\
\hline & Jarak & 0.498 & 0.810 & 0.440 & 1.490 \\
\hline \multirow[t]{2}{*}{ II } & Usia & 0.002 & 0.449 & 0.268 & 0.753 \\
\hline & Paritas & 0.044 & 0.589 & 0.352 & 0.985 \\
\hline
\end{tabular}

Hasil tabel 6 didapatkan dari analisis multivariat bahwa faktor yang paling berpengaruh terhadap perdarahan postpartum adalah paritas. Hasil multivariat antara paritas dengan perdarahan postpartum didapatkan $\operatorname{Exp}(B)=0.589$ artinya paritas primipara dan grandemultipara 0.589 kali beresiko mengalami perdarahan post partum dibandingkan paritas multipara.

\section{PEMBAHASAN}

\section{Hubungan Paritas dengan Perdarahan Post Partum}

Hasil penelitian didapatkan ada hubungan paritas dengan perdarahan post partum dan paritas primipara dan grandemultipara 1.69 kali beresiko mengalami perdarahan post partum dibandingkan paritas multipara. Hal ini sejalan dengan penelitian Puspasari (2017) terdapat hubungan antara variabel paritas dengan variabel perdarahan postpartum. Besarnya risiko relatif pendarahan postpartum pada kelompok ibu dengan paritas $>4$ memiliki risiko 7 kali dibandingkan kelompok ibu dengan paritas 2 - 4. Penelitian Purwanti dkk (2015) ibu yang paritasnya lebih dari 3 berisiko 2.2 kali lebih besar mengalami perdarahan post partum karena atonia uteri dibandingkan dengan ibu yang memiliki anak 1 atau 2.

Penelitian yang dilakukan Darmayanti (2014) menunjukkan paritas risiko (>3) memililiki resiko 3 kali lebih besar untuk terjadinya retensio plasenta, hal ini sesuai dengan teori bahwa paritas tinggi (lebih dari tiga) mem-punyai angka kejadian perdarahan pasca persalinan lebih tinggi, hal ini di hubungkan dengan fungsi reproduksi ibu bersalin yang mengalami penurunan karena seringnya hamil atau melahirkan.

Wanita dengan riwayat paritas lebih dari sama dengan 4 kali hal ini mungkin disebabkan oleh karena adanya gangguan elastisitas otot-otot uterus. Kelainan otot uterus terjadi akibat berulang-ulang mengalami peregangan karena kehamilan sehingga terjadi gangguan pada otot-otot uterus untuk berkontraksi sesaat setelah kelahiran bayi yang mengakibatkan timbulnya perdarahan (Rifdiani, 2016). Paritas yang rendah (paritas satu), ketidaksiapan ibu dalam menghadapi persalinan menyebabkan ketidakmampuan ibu hamil dalam menangani komplikasi yang terjadi selama kehamilan, persalinan dan nifas (Manuaba, 2009).

Pada responden yang perdarahan sebagian besar $(53.7 \%)$ dengan paritas primi dan grande. Penelitian ini sejalan dengan penelitian Saktriyandri (2017) diketahui bahwa dari 34 ibu yang bersalin dengan paritas berisiko ( 1 atau $>3$ ) sebanyak $12(35,3 \%)$ mengalami perdarahan postpartum. Hasil penelitian juga didapatkan bahwa dari responden yang memiliki paritas multi menyebabkan terjadinya perdarahan. Hal ini terjadi karena partus lama. Ibu yang mengalami partus lama mempunya peluang 1,1 kali untuk perdarahan postpartum dibanding dengan ibu yang tidak mengalami partus lama (Saktriyandri, 2017). Penelitan oleh Dina (2013) menyatakan bahwa partus lama merupakan faktor resiko perdarahan postpartum, dimana ibu yang mengalami partus lama mempunyai resiko 3,5 kali lebih besar untuk mengalami perdarahan post partum dibandingkan ibu yang tidak mengalami partus lama.

Selanjutnya, responden yang mempunyai paritas primi dan grande tidak mengalami perdarahan karena ibu melakukan ANC secara teratur sehingga bisa dideteksi secara dini faktor resiko penyebab perdarahan postpartum. Penelitian Murbiah (2015) menyebutkan bahwa 
frekuensi antenatal dengan kejadian perdarahan postpartum dengan $\mathrm{p}$ value 0,000 dengan nilai OR 13,95 yang berarti bahwa dengan frekuensi antenatal dapat berpeluang 13 kali terjadinya perdarahan pada ibu postpartum.

\section{Hubungan Umur dengan Perdarahan Post Partum}

Hasil penelitian didapatkan ada hubungan umur dengan perdarahan post partum dan umur $<20$ dan $>35$ tahun 2.22 kali beresiko mengalami perdarahan post partum dibandingkan umur 20-35 tahun. Penelitian ini sejalan dengan penelitian Purwanti dkk (2015) menyebutkan bahwa ibu yang memiliki umur kurang dari 20 tahun dan lebih dari 35 tahun 2.1 lebih besar mengalami perdarahan post partum dibandingkan dengan ibu yang berumur 2030 tahun.

Perdarahan terjadi pada umur >35 tahun dikarenakan fungsi organ reproduksi juga menurun. Fungsi organ reproduksi terutama uterus dimana otot uterus harus berkontraksi maksimal sesaat setelah plasenta lahir agar tidak terjadi perdarahan. Kehamilan <20 tahun fungsi organ dan kematangan sel telur yang belum maksimal potensial mengalami persalinan dengan premature, plasenta previa, abortus, pre eklampsi, kondisi ini berisiko lebih besar terjadinya perdarahan (Purwanti, 2015).

Pada responden yang mengalami perdarahan postpartum sebanyak sebagian besar $(55.3 \%)$ responden memiliki umur $<20$ dan >35 tahun. Penelitian ini sejalan dengan penelitian Purwanti (2015) bahwa dari 80 responden yang mengalami atonia uteri mempunyai umur berisiko 36 responden (45\%). \Respoden yang memiliki umur 2035 tahun juga mengalami perdarahan dikarenakan adanya penggunaan okstosin drip selama persalinan dikarenakan tidak adekuatnya his. Penelitian saktriyandri (2017) menyatakan bahwa ibu yang bersalin dengan oksitosin drip memiliki peluang 8,2 kali mengalami perdarahan postpartum.

Selanjutnya, responden dengan umur $<20$ dan >35 tahun tidak terjadi perdarahan post partum dikarenakan dilakukan penatalaksanaan kala III yang baik penelitan yang dilakukan oleh Sosa et al (2009) menunjukkan bahwa pelaksanaan manajemen aktif kala III persalinan oleh petugas kesehatan dapat menurunkan risik o perdarahan postpartum sebesar $52 \%$ dengan kata lain tidak dilakukannya manajemen aktif kala III persalinan dapat meningkatkan risiko perdarahan postpartum pada ibu 2,08 kali lebih besar

\section{Hubungan Jarak Kelahiran dengan Perdarahan Post Partum}

Hasil penelitian tidak ada hubungan jarak kelahiran dengan perdarahan post partm dan jarak kelahiran <2 tahun 1.392 kali beresiko mengalami perdarahan post partum dibandingkan jarak kelahiran $\geq 2$ tahun. Hasil penelitian ini tidak sejalan dengan penelitian Rifdiani (2016) terdapat hubungan antara jarak kelahiran dengan perdarahan post partum. Risiko ibu mengalami perdarahan dengan jarak kehamilan $<2$ tahun adalah 17,953 kali lebih besar dibandingkan dengan ibu yang jarak kehamilannya $\geq 2$ tahun. Penelitian Puji (2015) menunjukkan ada hubungan antara jarak kehamilan dengan kejadian perdarahan postpartum dengan $\mathrm{p}$ value 0,001 dengan OR 17,333 kali yang berarti jarak kehamilan mempunyai peluang 17 kali dapat menyebabkan terjadinya kejaidan perdarahan postpartum.

Jarak antar kelahiran dengan anak sebelumnya kurang dari 2 tahun, menyebabkan rahim dan kesehatan ibu belum pulih dengan baik. Rahim yang belum pulih menyebabkan kontraksi uterus pasca melahirkan tidak teratur yang mengakibatkan terjadinya perdarahan post partum (Manuaba, 2009). Responden yang memiliki jarak $\geq 2$ tahun juga mengalami perdarahan post partum dikarenakan ada riwayat perdarahan postpartum sebelumnya. Penelitian Rifdiani (2016) risiko ibu mengalami perdarahan postpartum yang memiliki riwayat perdarahan postpartum sebelumnya adalah 18,104 kali lebih besar dibandingkan ibu yang tidak memiliki 
riwayat perdarahan postpartum pada persalinan sebelumnya.

Faktor lain yang menyebabkan ibu dengan jarak $\geq 2$ tahun mengalami perdarahan post partum adalah bayi besar, Supa dan Sondang (2012), yang menyatakan bahwa ada hubungan antara ukuran bayi atau berat bayi lahir dengan kejadian perdarahan postpartum. Kondisi melahirkan dengan bayi makrosomia ( $\geq 4000$ gram) dapat menyebabkan perdarahan post partum karena uterus meregang terlalu berlebihan dan membuat kontraksi melemah.

Selanjutnya, responden yang memiliki jarak $<2$ tahun tidak mengalami perdarahan dikarenakan ibu mempunyai status gizi yang baik. Penelitian Murbiah (2015) menunjukkan bahwa status gizi berpengaruh terhadap kejadian perdarahan postpartum dan status gizi buruk 19,2 kali berpeluang terjadinya kejadian perdarahan postpartum daripada status gizi baik.

\section{Hubungan Anemia dengan Perdarahan Post Partum}

Hasil penelitian tidak ada hubungan anemia dengan perdarahan post partum dan anemia bukan merupakan faktor resiko perdarahan post partum. Penelitian ini tidak sejalan dengan penelitian Saktriyandri (2017) menyatakan bahwa terdapat hubungan antara anemia dengan perdarahan postpartum di RSUD Panembahan Senopati Bantul Tahun 2015 dan ibu yang bersalin dengan anemia memiliki peluang 4,8 kali mengalami perdarahan postpartum dibanding ibu yang tidak anemia.

Risiko perdarahan postpartum meningkat pada wanita bersalin dengan anemia berat, dimana uterus kekurangan oksigen, glukosa dan nutrisi esensial, cenderung bekerja tidak efisien pada semua persalinan, hal inilah yang dapat menyebabkan perdarahan postpartum semakin meningkat (Manuaba, 2009).

Responden yang tidak anemia banyak yang mengalami perdarahan disebabkan oleh jenis persalinan dan terjadinya over distensi pada uterus ibu yang berlebihan. Persalinan dengan tindakan merupakan salah satu faktor penyebab terjadinya perdarahan postpartum. Persalinan dengan tindakan diantaranya adalah persalinan tindakan pervaginam yaitu dengan vakum dan forsep, sedangkan tindakan persalinan per abdominal adalah SC. Tindakan pada persalinan baik vaginam maupun abdominal dapat menyebabkan trauma baik pada ibu maupun pada bayi (Manuaba, 2009).

Selanjutnya, responden yang anemia tidak mengalami perdarahan dikarenakan ibu meminum tablet Fe secara teratur dan mengkonsumsi dengan cara benar. Penelitian Anasari (2012) menunjukkan hubungan antara kepatuhan ibu hamil mengkonsumsi tablet $\mathrm{Fe}$ dengan kejadian anemia di Desa Pageraji Kecamatan Cilongok Kabupaten Banyumas. semakin baik kepatuhan ibu dalam mengkonsumsi tablet $\mathrm{Fe}$ maka semakin rendah resiko ibu mengalami anemia.

\section{KESIMPULAN}

Hasil penelitian ada hubungan paritas dengan perdarahan post partum ( $p$ value $=0.041, \quad \mathrm{OR}=1.691)$, tidak ada hubungan jarak kelahiran dengan perdarahan post partum ( $p$-value $=0.199, \quad \mathrm{OR}=1.392)$, ada hubungan umur kelahiran dengan perdarahan post partum ( $p$-value $=0.002$, $\mathrm{OR}=2.220$ ) dan tidak ada hubungan anemia dengan perdarahan post partum ( $p$ value $=0.294, \quad \mathrm{OR}=0.759)$. Faktor yang paling berpengaruh terhadap perdarahan post partum adalah paritas ( $p$-value $=0.044$, $\mathrm{OR}=0.589$ ). Khusus pada ibu yang akan bersalin dlakukan deteksi yang spesifik dan komprehensif terutama bagi ibu primi atau grandemultipara terutama pada saat kala III dan IV dengan melakukan tindakan manajemen aktif kala III sehingga mencegah terjadinya atonia uteri. 


\section{DAFTAR RUJUKAN}

BAPPENAS. 2017. SDG'S Indonesia Diakses dalam http://www.sdgsindonesia.or.id/ tanggal 3 Juni 2017 pukul 20.00 WIB

Cunningham.2010. Obstetri Williams Edisi 2.EGC.Jakarta

Darmayanti. 2014. Faktor-Faktor yang Berhubungan dengan Kejadian Retensio Plasenta di RSUD Dr.H.Moch.Ansari Saleh Banjarmasin. Jurnal An Nadaa 1(2):77-81

Diana. 2013. Analisis Faktor-Faktor Yang Berhubungan Dengan Komplikasi Obstetri Ibu Dan Bayi Di Kecamatan Parongpong Kabupaten Bandung Barat. Tesis. Program Pasca Sarjana Ilmu Kesehatan Masyarakat. Universitas Padjajaran

Fatbinan dkk. 2010. Faktor Risiko Kematian Maternal di RSUD Piere Paolo Magreti Saumlaki Kabupaten Maluku Tenggara Barat. Skripsi. Fakultas Kesehatan Masyarakat Universitas Hasanuddin Makassar

Fitria. 2016.Hubungan Anemia Dengan Perdarahan Postpartum di RSUD Abdul Moeloek Bandar Lampung Tahun 2016. Jurnal Kebidanan 2(2):56-60

Hardisman. 2013. Memahami Patofisiologi dan Aspek Klinis Syok Hipovolemik: Update dan Penyegar. Jurnal Kesehatan Andalas 2(3):178182

Hidayah, dkk.2013. Faktor-faktor yang Mempengaruhi Perdarahan Postpartum Primer di RSUD Panembahan Senopati Bantul Tahun 2013. Naskah Publikasi. Universitas "Aisyiyah" Yogyakarta

Kemenkes RI.2014. Profil Kesehatan Indonesia. Jakarta

Manuaba. 2009. Pengantar Kuliah Obstetri: Perdarahan Postpartum. EGC.Jakarta.

Manuaba. 2012. Pengantar Kuliah Obstetri.Jakarta. EGC.

Murbiah.2015. Faktor-Faktor Yang Berhubungan Dengan Kejadian Perdarahan Postpartum Di
Rumah Sakit Muhammadiyah Palembang Tahun 2015. Program Studi Ilmu Keperawatan STIKes Muhammadiyah Palembang.

Nugroho.2012. Patologi Kebikdanan. Yogyakarta. Nuha Medika.

Pujiana.2015. Faktor-Faktor yang Berhubungan dengan Kejadian Perdarahan Postpartum di Rumah Sakit Muhammadiyah Palembang Tahun 2015. Jurnal Program Studi Ilmu Keperawatan STIKes Muhammadiyah Palembang 3(2):22-29.

Purwanti, dkk.2015.Determinan Faktor Penyebab Kejadian Perdarahan Post Partum Karena Atonia Uteri. Naskah Publikasi. Akademi Kebidanan YLPP Purwokerto.

Puspasari.2017.Hubungan antara umur dan paritas dengan perdarahan postpartum di RSKIA Kota Bandung. Jurnal Ilmiah Indonesia 2(7):69-81.

Queensland Maternity and Neonatal Clinincal Guidelines Program.2013. Primary Post Partum Hemorraghe, MN12.1-V4-R17.State of Queensland (Queensland Health).

Rifdiani.2016.Pengaruh Paritas, BBL, Jarak Kehamilan dan Riwayat Perdarahan Terhadap Kejadian Perdarahan Postpartum. Jurnal Berkala Epidemiologi 4(3):396-407.

Saktiyandri dkk.2017. Faktor-faktor yang Mempengaruhi Kejadian Perdarahan Postpartum. Journal of Health Studies 1(1): 49-64.

Sari. 2015. Hubungan Paritas Dengan Kejadian Perdarahan Postpartum Primer Pada Ibu Bersalin di Puskesmas Mergangsangan. Skripsi. Universitas "Aisyiyah Yogyakarta.

Wardani.2017. Faktor yang mempengaruhi terjadinya perdarhan pasca persalinan. Jurnal Ilmu Kesehatan 2 (1):51-60.

World Health Organization (WHO). 2014. Trends in maternal mortality: 1990 to 2013. 